\title{
Local heat flux measurements in a hydrogen and methane spark ignition engine with a thermopile sensor
}

\author{
J. Demuynck*,, N. Raes, M. Zuliani, M. De Paepe, R. Sierens, S. Verhelst \\ Ghent University, Department of Flow, Heat and Combustion Mechanics, \\ Sint-Pietersnieuwstraat 41 B-9000 Gent, Belgium
}

\begin{abstract}
This paper describes an experimental investigation of heat transfer inside a CFR spark ignition engine operated at a constant engine speed of $600 \mathrm{rpm}$. The heat flux is directly measured under motored and fired conditions with a commercially available thermopile sensor. The heat transfer during hydrogen and methane combustion is compared examining the effects of the compression ratio, ignition timing and mixture richness. Less cyclic and spatial variation in the heat flux traces are observed when burning hydrogen, which can be correlated to the faster burn rate. The peak heat flux increases with the compression ratio, but the total cycle heat loss can decrease due to less heat transfer at the end of the expansion stroke. An advanced spark timing and increased mixture richness cause an increased and advanced peak in the heat flux trace. Hydrogen combustion gives a heat flux peak which is three times as high as the one of methane for the same engine power output.
\end{abstract}

Key words: hydrogen, methane, internal combustion engine, experimental, heat transfer, thermopile

\section{Nomenclature \\ Abbreviations \\ ${ }^{\circ} \mathrm{CA}$ degree crank angle \\ $\mathrm{NO}_{\mathrm{x}}$ oxides of nitrogen \\ ABDC after bottom dead centre \\ ATDC after top dead centre \\ BBDC before bottom dead centre \\ BTDC before top dead centre \\ CFR Cooperative Fuel Research \\ COV coefficient of variation \\ DI direct injection \\ EGR exhaust gas recirculation}

${ }^{*}$ Corresponding author. Tel.: +32(0)92643302; Fax: +32(0)92643590
Email address: joachim. demuynck@ugent. be (J. Demuynck) 


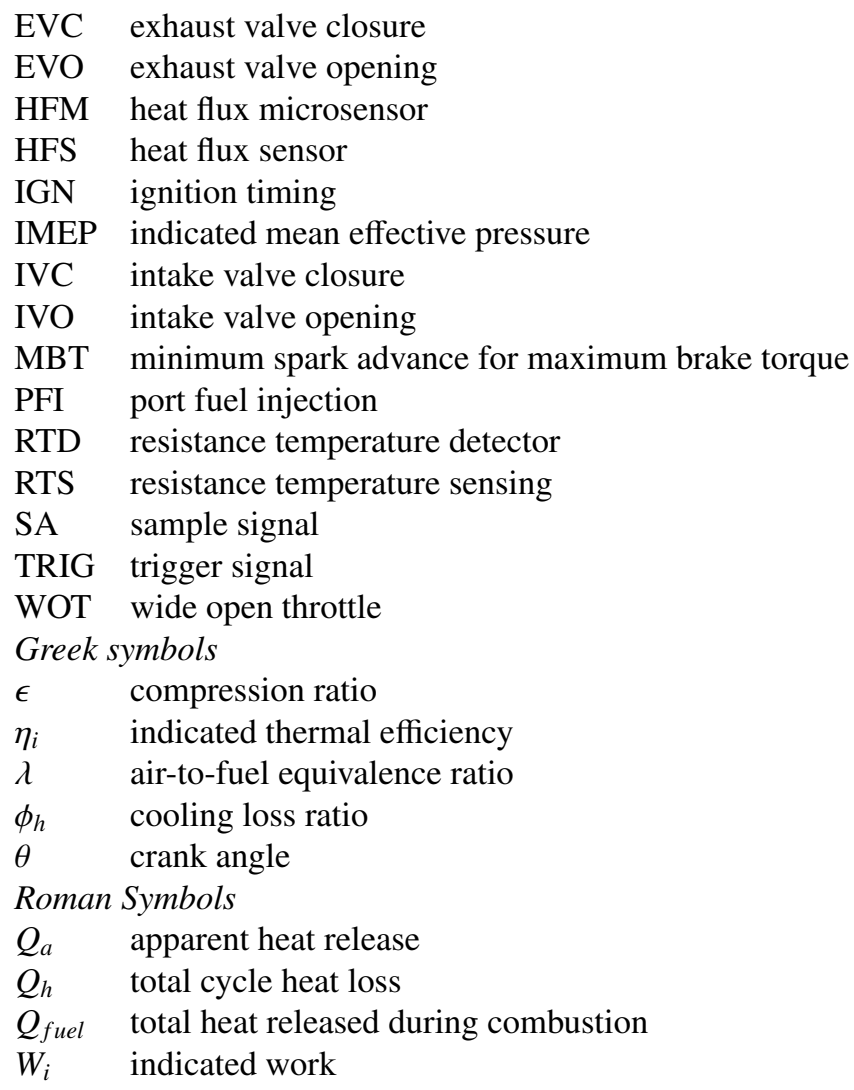

\section{Introduction}

Hydrogen-fuelled internal combustion engines are attractive as they offer the potential of near-zero noxious emissions [1], high efficiency [2] and zero greenhouse gas emissions [3]. Computer simulation of the engine cycle enables a cheap and fast optimization of engine settings for operation on hydrogen. A quasi-dimensional simulation model, the GUEST-code (Ghent University Engine Simulation Tool) has been developed by Verhelst and Sierens [4]. The model has been used to simulate power output and efficiency, with good accuracy, and will be expanded with emission calculations. These are a prerequisite as the control of emissions is an important constraint for power and efficiency optimization. Consequently, it is important to describe the heat transfer from the burning gases to the cylinder walls in a sub-model in order to calculate the maximum gas temperature which influences the emissions of oxides of nitrogen $\left(\mathrm{NO}_{\mathrm{x}}\right)$. These emissions occur in a hydrogen engine at high loads. Several models to describe heat transfer in engines exist but are cited to be inaccurate for hydrogen engines $[5,6]$. The current authors are developing a new model for the heat transfer in hydrogen engines. In order to validate this model, measurements inside an engine have been carried out. 


\section{Heat transfer in internal combustion engines}

\subsection{Measurement methods}

A brief overview of existing methods to measure heat transfer in combustion engines is given in order to fully understand the following sections. Several methods have been developed since Bendersky [7] presented his fast response thermocouple. The heat released during combustion is transferred to the cylinder walls by convection and radiation. It is further transferred through the walls to the coolant by conduction. It is very difficult to measure the convective and radiative heat transfer inside the combustion gases so all the methods measure it indirectly in the cylinder walls. The most common way is to calculate the heat transfer with equation 1 which describes the heat transfer through the sensor body. $\mathrm{Q}$ is the heat transfer, $\mathrm{A}$ is the surface of the sensor body, $\mathrm{k}$ is the conduction coefficient of the sensor material, $\mathrm{T}$ is the temperature, $\mathrm{x}$ is the distance measured from the inner wall surface.

$$
\dot{q}=\frac{Q}{A}=-k \cdot \frac{d T}{d x}
$$

The temperature as a function of the location in the wall is calculated out of the Fourier equation, given in equation 2 with $\alpha$ being the thermal diffusivity. The derivative of the temperature at $x=0$ is substituted in equation 1 to calculate the heat transfer at the gas-wall interface.

$$
\frac{\partial T}{\partial t}=\alpha \cdot \frac{\partial^{2} T}{\partial^{2} x}
$$

Two boundary conditions are necessary to solve equation 2 . The wall surface temperature as a function of time is the first boundary condition and this can be measured with a fast response thermocouple or an RTD (Resistance Temperature Detector). There are two possibilities for the second boundary condition. First of all a second temperature measurement in the cylinder wall at a known distance from the surface can be used as described by Annand [8]. This calculation supposes one dimensional heat transfer between the two temperature measurements. Care has to be taken to ensure this one dimensional heat flow, because two and three dimensional effects can influence the accuracy of the measurement as described by Buttsworth [9]. A second possibility is to assume zero heat flux at the moment the gas temperature is equal to the wall temperature, as described by Woschni [10]. Therefore a bulk gas temperature in the cylinder has to be calculated out of a pressure measurement, using the equation of state. In this way only one temperature measurement is needed and this simplifies the sensor construction. There are some doubts however about the correctness of this method. Lawton [11] and Nijeweme et al. [12] have reported non-zero heat fluxes at the moment of equal wall and gas temperature.

An alternative for the two Fourier methods is the impulse response processing method of Oldfield [13]. It can be used to calculate the heat transfer based on the wall surface temperature. This method has been developed for heat transfer measurements in gas turbines and has already been used by Wang et al. [14] for measurements 
in internal combustion engines. To apply this method, the impulse response of the heat flux sensor has to be calibrated once in a test rig.

A second alternative is to calibrate the sensor so that its output can be correlated with the heat flux it measures (previous methods only calibrate the temperature sensors separately). This allows to obtain the heat flux directly out of the output signal without a calculation method. Accurate reference sensors and calibration test rigs are required for a good calibration.

In all cases, the transient surface temperature of the cylinder wall has to be measured to determine heat transfer rates in an internal combustion engine. Optionally a reference temperature measurement has to be included. Several sensors have been developed for this purpose which can be classified into four groups:

- Coaxial type: the two metals of the thermocouple are coaxially positioned and the junction is formed by a thin layer on top.

- Pair wire type: two wires of a thermocouple are inserted in a body which is not a part of the thermocouple pair, a thin layer is sputtered on top to form the junction.

- Film type: the thermocouple elements are thin layers which are deposited on each other.

- Thermistor type: a metal with a temperature dependent resistance (RTD) is used.

The use of these sensors to measure heat transfer in the research engine was investigated in a previous publication [15]. Several sensors were selected and will be compared to each other in future research. This paper describes measurements with a commercially available sensor of the film type which has the advantage that it is calibrated by the manufacturer so none of the aforementioned calculation methods have to be used. The dimensions of the sensor are a disadvantage, the outer diameter of $8.74 \mathrm{~mm}$ is quite large for engine research. This is not a problem for the research engine used here, as will be discussed further on.

\subsection{Heat transfer measurements in hydrogen engines}

A lot of research has been done on heat transfer in gasoline and diesel engines, but only a few research groups have investigated it in hydrogen engines. The most extensive research has been performed by teams working at the TU Graz and BMW. The research focused on investigating combustion concepts for hydrogen engines. Heat transfer measurements were an important part of the programme, examining its effect on thermal efficiency. Different measurement techniques were compared at the TU Graz by Wimmer et al. [16] and they concluded that the one temperature Fourier method is the most appropriate for research in combustion engines. This method has been used by TU Graz and BMW ever since, but it is not always mentioned which type of sensor is used. Wimmer et al. [17] compared heat transfer with hydrogen combustion to gasoline and concluded that the peak and total cycle heat transfer was larger for hydrogen. They investigated the two injection strategies which can be applied. The hydrogen can either be injected in the intake manifold (PFI, port fuel injection) or directly in the combustion chamber (DI, direct injection). Peak and total cycle heat transfer for 
DI is bigger than PFI according to Wimmer et al. [17] because the injection during compression augments the in-cylinder turbulence and consequently the heat transfer. Eichlseder et al. [18] however showed lower total cycle heat losses with stratified direct injection concepts. Both studies showed that the heat transfer to the cylinder walls is an important factor for efficiency optimization in hydrogen engines. Michl et al. [19] measured heat flux in the cylinder head and in the piston with coaxial type sensors (29 in total). They found that increasing the air-to-fuel equivalence ratio $(\lambda)$ was beneficial to bring down heat losses, but this decreases the power output. Therefore they used exhaust gas recirculation (EGR) to reduce the heat losses while preserving stoichiometric combustion.

Shudo et al. [20, 21, 22] have also done research on the heat transfer in hydrogen combustion engines, first with port fuel injection and later with direct injection. They measured the heat flux at a single location on the cylinder head using a coaxial type sensor together with the one temperature Fourier method. Heat loss derived from a rate of heat release analysis resulted in the same qualitative conclusions as the directly measured heat flux, so they did not use the measured heat flux in their analysis and have unfortunately only published some of those measurements. Their research focused on the improvement of thermal efficiency in a hydrogen engine. They investigated the influence of ignition timing and mixture richness and compared hydrogen to methane combustion. According to them hydrogen has a larger amount of cooling loss compared to methane. However, they did not give power output, load or fuel flow values so no clear comparison between their hydrogen and methane measurements can be made. It is noteworthy that their measurements showed that there is a bigger difference in cooling loss between methane and hydrogen than in thermal efficiency (around 20\% difference in cooling loss and only 5\% in indicated thermal efficiency). The thermal efficiency increased with increasing air-to-fuel equivalence ratio because of lower cooling losses. This agrees with the findings of Michl et al. [19], but Shudo et al. [20] have not mentioned anything about the consequence on power output. Retarded ignition timing also decreased cooling loss, but this did not increase thermal efficiency because of the resulting lower degree of constant volume combustion. They found stratified direct injection to be the best strategy to increase the thermal efficiency of hydrogen engines (only based on measurements in a constant volume chamber [22]), which agrees with the conclusions of Eichlseder et al. [18].

Wei et al. [5] investigated the heat transfer in a spark ignited hydrogen engine with dual injection (port fuel at low loads and direct injection at high loads) and compared it with gasoline. They installed four coaxial type sensors in the cylinder head and used the two temperature Fourier method. The measured heat flux varied significantly with the measurement position. They strangely concluded however that a spatial averaged heat flux is most desirable to investigate heat transfer in the cylinder head. The peak of the heat flux was 2.5 times larger on hydrogen compared to gasoline under the same engine speed and load (the load is only given in terms of percentage, so it is not clear if it is really the same load). Hydrogen combustion however resulted in a lower heat flux during expansion which is an indication of the faster burn rate.

It is clear that knowledge about the heat transfer in hydrogen engines is very important for power and efficiency optimization. There are indications that the heat transfer 
is higher than for gasoline or methane. The shorter quenching distance and higher laminar burning velocity are put forward as explanations. Some aspects are however missing in the literature and others need confirmation:

- Heat transfer measurements between hydrogen and other fuels have been compared, but their is a lack of measurements that can be compared based on a logically defined engine parameter which is kept constant (e.g. measurements with an equal power output or equal heat input).

- Most of the researchers have used the one temperature Fourier method, but its accuracy needs further examination.

- The change in heat transfer according to the measurement position has to be investigated more thoroughly.

- The effect of heat losses on thermal efficiency has been investigated, but its correlation with emissions has not been described.

Heat flux traces in spark ignited gas engines are very rare in the literature. Only three publications describe heat flux traces of methane or hydrogen in detail $[5,18,20]$. The publication of such heat flux traces are very important for the validation of any kind of cycle simulation tool. In this paper heat transfer measurements inside a spark ignition engine with a thermopile sensor are described. First measurements are taken under motored operation to decouple the effects of flow and turbulence from combustion. Then the difference between hydrogen and methane is investigated under fired operation. Heat flux measurements are performed on both fuels at different positions in the cylinder to examine spatial variations. Additionally the ignition timing, compression ratio and air-to-fuel equivalence ratio are varied to examine the influence of these parameters on the heat flux.

\section{Experimental equipment}

\subsection{Test engine}

The engine used in this research is a four-stroke single-cylinder spark ignited gas engine based on a CFR (Cooperative Fuel Research) engine [23] operated at a constant speed of $600 \mathrm{rpm}$. It is equiped with PFI and a variable compression ratio. The details of the engine are given in Table 1. A cross section of the CFR-cylinder is shown in Fig. 1. A thermosiphon filled with water is used as a cooling system. The water boils at the cylinder wall (constant temperature of $100^{\circ} \mathrm{C}$ ) and rises to the top of the thermosiphon where it is cooled by external cooling water. Fuel injection and ignition timing are controlled by a MoTeC M4Pro electronic control unit.

\subsection{Measuring equipment}

An overview of the measuring equipment is shown in Fig. 2. In this paper a commercially available heat flux sensor was used. It is an uncoated Vatell HFM-7 sensor which consists of a thermopile (heat flux signal, HFS) and an RTD (substrate temperature signal, RTS). A thermopile is a series connection of thermocouple pairs which 
measure the temperature difference over a very small resistance layer. The sensor has a response time of $17 \mu \mathrm{s}$. The Vatell AMP-6 amplifier was used as a current source for the RTD and as an amplifier for both output signals. The lowest selectable gain of the AMP- 6 was too high for measurements under fired conditions as the output signal saturated. Without gain, the accuracy of the acquisition was too low so an additional instrumentational amplifier was constructed. As the test engine is easily accessible, the heat flux sensor could be installed in three different positions (P2, P3, P4 as shown in Fig. 1). These openings are placed at the same height in the cylinder wall and are equally distributed around the circumference of the cylinder. The spark plug was placed in position P1 (this position is available for heat transfer measurements under motored conditions). The measurement position is mentioned in the caption of all the figures in the following sections.

In-cylinder pressures were measured using a water-cooled, flush-mounted Kistler $701 A$ piezoelectric pressure sensor with a Kistler 5011 amplifier. Inlet pressure was measured using a Kistler $4075 \mathrm{~A} 20$ piezoresistive pressure sensor with a Kistler $4618 \mathrm{AO}$ amplifier. This inlet pressure was used to reference in-cylinder pressure. A 12 bit data acquisition card (Keithley DAS58) was used to sample both the heat flux and pressure signals. It is triggered by a COM crank angle encoder. The signal is interpolated with a COM type 2614 interpolar and gives a signal every $0.1^{\circ} \mathrm{CA}$ (sample signal, SA) and an extra one every two cycles (trigger signal, TRIG). This results in a sampling rate of $36 \mathrm{kHz}$. Gas flows were measured with Bronkhorst Hi-Tec F-201AC (fuel) and $F-106 B Z$ (air) flow sensors. Type $\mathrm{K}$ thermocouples were used to measure inlet and exhaust gas temperatures.

\subsection{Error analysis}

To judge the quality of the measurement results, a thorough error analysis has been carried out following the methods described in Taylor [24]. This analysis is based on the accuracy of the measurement equipment, given in Table 2. The important (worst case) results of the analysis are given below.

The heat flux has a relative error of $3 \%$ and the substrate temperature is measured with an accuracy of $7 \%$. The measured wall temperatures have peak-to-peak values of around 5 to $10^{\circ} \mathrm{C}$. They can be considered constant bearing in mind that the absolute measurement error goes up to $14^{\circ} \mathrm{C}$ and that gas temperatures vary up to $2000^{\circ} \mathrm{C}$ within an engine cycle. The wall temperatures given in the following sections are therefore cycle averaged values.

The uncertainty on $\epsilon$ is negligible. The relative error on the gas flows are $3 \%$ (air) and $4 \%$ (fuel). The absolute error on the engine speed is $6 \mathrm{rpm}$ and on the ignition timing it is $0.5^{\circ} \mathrm{CA} . \lambda$ and $W_{i}$ are determined with an accuracy of respectively 5 and $1 \%$. $Q_{h}$ is calculated with an accuracy of $3 \%, Q_{f}$ has a relative error of $4 \%$. The relative error on $\eta_{i}$ is $4.1 \%$ and on $\phi_{h}$ it is $5 \%$.

\section{Results and discussion}

Measurements were taken under motored and fired conditions at different positions inside the combustion chamber to investigate spatial variation of heat fluxes. The com-

pression ratio and position of the throttle valve were varied under motored condition to 
assess the influence of in-cylinder flow and turbulence. Under fired condition the compression ratio $(\epsilon)$, ignition timing (IGN) and air-to-fuel equivalence ratio $(\lambda)$ were varied. For these cases all measurements were performed with wide-open-throttle (WOT) except one measurement on methane to equal the power output of hydrogen as will be shown later on.

The most common way found in the literature is to display the heat flux trace of the ensemble cycle. The heat flux of the ensemble cycle at a certain crank angle $(\theta)$ is the average of all the heat fluxes of an entire measurement set at that crank angle. The sum of the quadratic deviations from the ensemble cycle is used to determine the minimum, maximum and best fitting cycle. In this paper heat flux traces of the ensemble cycle are shown (unless mentioned otherwise) and a measurement set always consists of 35 cycles. The ignition sometimes disturbs the HFS-signal which can be seen in some of the following figures.

An estimate of the bulk gas temperature (between IVC and EVO) has been made based on the equation of state and the measured in-cylinder pressure. The specific gas constant $(\mathrm{R})$ and trapped mass are two unknown variables that have to be calculated. $\mathrm{R}$ is kept constant between IVC and EVO and is taken at initial conditions as the mass average of the specific gas constants of the air, fuel and residual gases. The composition of the residuals is for each fuel calculated out of the chemical equation of combustion. The trapped mass is the sum of the measured incoming mass (air and fuel) and the residuals. There is no valve overlap for the test engine so no incoming mass goes directly to the exhaust manifold. The residual mass is therefore determined with the equation of state at EVC using the measured cylinder pressure and assuming that the in-cylinder temperature is equal to the measured exhaust temperature.

Total cycle heat losses $\left(Q_{h}\right)$ are calculated assuming that the measured heat flux trace at a given position (in this paper at P2) occurs evenly over the entire cylinder wall. The measured heat flux is multiplied with the total available in-cylinder surface for each sampling point and all these values are summed up to get the total cycle heat loss. This is not entirely correct because of the spatial variation in heat flux (will be shown later on) but it gives an estimate of total cycle heat losses.

\subsection{Motored operation}

Figure 3 plots measured heat fluxes in motored operation, with only air entering the engine. Figure 3(a) shows that the heat flux varies a lot according to the measurement position during the intake stroke because of differences in local air flow. The heat flux is negative so heat is flowing from the wall to the incoming air. A decrease in the heat flux trace in that case actually means an enhancement in the heat transfer. Figure 3(a) shows that the heat flux trace starts to decrease simultaneously at positions P1, P2 and P3 after intake valve opening (IVO). The heat flux decreases at P4 with a time delay because this position is further away from the intake valve and it takes a while before the incoming air reaches it. The strong fluctuations in the heat flux traces in Fig. 3(a) are caused by changes in the gas velocity due to pressure waves in the intake manifold. Figure 3(b) shows that a pronounced spatial variation does not occur during the compression and expansion stroke. Differences are within the experimental uncertainty, e.g. $0.75 \cdot 10^{4} \mathrm{~W} / \mathrm{m}^{2}$ (an uncertainty range of $6 \%$ around $12.5 \cdot 10^{4} \mathrm{~W} / \mathrm{m}^{2}$ ) for the peak values. 
A decrease in the throttle opening decreases the trapped mass. This decreases the in-cylinder pressure and temperature and therefore a decrease in the heat transfer would be expected. Figure 4 shows however that up until a certain decrease in throttle opening (between WOT and the $75^{\circ}$ position) the heat flux increases due to an increase in turbulence. Both peak and total cycle heat flux rise. The figure shows that the heat transfer decreases again when the throttle position passes $75^{\circ}$ because the trapped mass is reduced too strongly (air flow values are given in the index of the figure). This reduces the cylinder pressure and gas temperature.

Increasing the compression ratio resulted in an increase in the heat flux because of a higher gas temperature (not shown here).

\subsection{Fired operation}

Subsequently, experiments were performed with combustion, using hydrogen and methane. Measurements on the combustion of hydrogen were executed in a similar way as those with methane. Due to the high flame propagation velocity of hydrogen, different ignition timings had to be chosen. Unless otherwise specified, measurements were done with ignition at TDC for hydrogen and $30^{\circ} \mathrm{CA}$ BTDC for methane which are MBT-timings for the stoichiometric WOT case at an $\epsilon$ of 8 .

Figure 5 displays the minimum, maximum, ensemble and best fitting cycle of a measurement set on methane and hydrogen at P2. The figure shows that great cyclic variations occur within a single set of heat flux measurements, but less so for hydrogen compared to methane. This can be related to the coefficient of variation (COV) of indicated mean effective pressures. The COV-value, calculated from pressure measurements, is noticeably lower with hydrogen (around $0.4 \%$ compared to $0.7 \%$ for methane) because of the faster flame propagation.

\subsubsection{Measuring position}

Figure 6 displays the heat flux trace at the three measurement positions around the circumference of the cylinder liner. The apparent rate of heat release $(d Q / d \theta)$ is plotted as well to give an idea about the combustion process. $d Q / d \theta$ is the difference between the heat released during combustion and the heat transfer to the walls. It is calculated out of the cylinder pressure (p) and volume (V) with equation 3 according to [25], $\gamma$ is taken equal to 1.35 .

$$
\frac{d Q_{a}}{d \theta}=\frac{\gamma}{\gamma-1} \cdot p \cdot \frac{d V}{d \theta}+\frac{1}{\gamma-1} \cdot V \cdot \frac{d p}{d \theta}
$$

For methane the heat flux first starts to increase at P2, then at P4 and ultimately at $\mathrm{P} 3$. This difference in the compression stroke was not the case under motored conditions as shown before in Fig. 3(b). This means the heat flux only starts to rise rapidly when the flame passes the measurement position. Heat flux measurements can therefore also be used to examine how the flame travels inside the combustion chamber and an estimate of flame speeds can be derived.

Figure 6 clearly shows the difference in flame propagation between methane and hydrogen. The methane flame first arrives at the position closest to the spark plug and the inlet valve (P2) and then at the position closest to the exhaust valve (P4). Since 
the distances between the spark plug and both $\mathrm{P} 2$ and P4 are equal, the difference in flame arrival times indicates a bulk in-cylinder flow. Through Schlieren visualisations in a CFR engine, Namazian et al. [26] found that the intake jet causes a vortex type flow in the upper corners of the cylinder. This rotating motion near the inlet valve persists through compression, combustion and expansion and shifts the centre of the spherical flame towards the intake valve. This means there is a non-symmetrical flame propagation. Figure 6(b) shows that there is no significant difference in flame arrival time between positions P2 and P4 for hydrogen. This suggests that the heat flux is less affected by bulk in-cylinder flow than with methane due to the higher burn rate. The flame ultimately arrives for both fuels at the position furthest from the spark plug (P3). The total cycle heat flux for both fuels is larger for P2 where the flame first arrives, but Fig. 6 shows that the peak heat flux is largest for P4 which is closest to the exhaust valve. The wall temperature varies up to $30^{\circ} \mathrm{C}$ according to the measurement position, for methane and hydrogen. The rate of heat release trace clearly confirms the difference in the combustion process between methane and hydrogen. For hydrogen, the combustion takes place in a very short period with a high heat release rate. The peak in the heat release rate is about 5 times higher for hydrogen compared to methane.

\subsubsection{Compression ratio}

Measurements were performed at a compression ratio of 6,8 and 10 with both fuels. Due to excessive engine loads under stoichiometric conditions on compression ratio 10 when burning hydrogen, all the measurements for varying $\epsilon$ on hydrogen were done at $\lambda=1.5$. Measurements on methane combustion were done at $\lambda=1$. According to Heywood [25] several operational properties change with increasing $\epsilon$ : the gas pressure and peak burned gas temperature increase, gas motion increases, combustion is faster and the gas temperature late in the expansion stroke decreases. The first four properties increase the heat transfer, the last one decreases it.

Figure 7(a) displays the heat flux traces for methane at P2. The peak and total cycle heat flux increase with higher compression ratios due to higher in-cylinder temperatures during the beginning phase of the combustion. IMEP (indicated mean effective pressure) increases from 7.5 to 8 bar. The calculated maximum gas temperature does not rise however with increasing $\epsilon$. This is due to the fact that a higher $\epsilon$ causes a decrease in the trapped mass which decreases the energy released during combustion. The maximum gas temperature is around $1960^{\circ} \mathrm{C}$ for the three cases. The higher temperatures around TDC also influence the flame propagation. This is visible in Fig. 7(a): at higher compression ratios, the heat flux starts to rise sooner indicating the faster combustion. The heat flux at $\mathrm{P} 2$ starts to rise rapidly at $3^{\circ} \mathrm{CA}$ BTDC for an $\epsilon$ of 6 . At an $\epsilon$ of 8 , the time the flame passes the sensor advances by about $6^{\circ} \mathrm{CA}$, and another $2^{\circ} \mathrm{CA}$ for an $\epsilon$ of 10 . Figure 7(a) shows that at the end of the expansion stroke the heat flux decreases with increasing compression ratio because of a lower gas temperature. The wall temperature increases with $\epsilon$ from 163 to $193^{\circ} \mathrm{C}$.

For hydrogen similar phenomena can be observed In Fig. 7(b), although the influence of the compression ratio on the initial phase of combustion is much smaller. The difference in flame arrival time between compression ratios 6 and 10 is only $2^{\circ} \mathrm{CA}$. IMEP increases from 5.1 to 5.3 bar. Higher compression ratios cause higher peak heat fluxes due to higher in-cylinder temperatures around TDC (maximum gas temperature 
after TDC is again equal for the three cases, around $1630^{\circ} \mathrm{C}$ ). For hydrogen the total cycle heat flux is however lowest for an $\epsilon$ of 10 because of the lower heat flux at the end of the expansion stroke. The trend in heat flux at the end of the expansion stroke between a compression ratio of 6 and 8 is contrary to the one observed for methane, see Fig. 7(a). An increase in $\epsilon$ causes an increase in heat flux although the calculated gas temperature is lower for an $\epsilon$ of 8 . This needs further investigation. The wall temperature increases from 146 to $158^{\circ} \mathrm{C}$.

According to Heywood [25] total cycle heat loss in a SI engine should decrease with an increasing compression ratio until $\epsilon=10$ because the lower gas temperature in the expansion stroke dominates the other effects. The other trends are dominating for even higher compression ratios and therefore heat flux should start to increase for an increase in $\epsilon$ above 10 . Here only a range in $\epsilon$ beneath 10 could be tested and the trend predicted by Heywood is not observed. The heat fluxes at the end of the expansion stroke do decrease, but they do not cause a decrease in the total cycle heat loss. This is only the case for $\epsilon=10$ for hydrogen. This can be caused by the fact that ignition timing has been kept constant for the different compression ratios. A higher $\epsilon$ causes a faster combustion so the timing could be retarded which has a strong effect on the heat flux (see next paragraph). A second possible explanation is the assumption in the total cycle heat loss calculation since the heat flux trace at $\mathrm{P} 2$ is assumed to be representative for the entire cylinder surface.

\subsubsection{Ignition timing}

Because of the difference in flame propagation, there is a great difference in ignition timings between methane and hydrogen combustion. While the MBT-timing $(\lambda=1$, $\mathrm{CR}=8$, WOT) of methane is found to be around $30^{\circ} \mathrm{CA} \mathrm{BTDC}$, it is around TDC for hydrogen. To be able to compare the influence of ignition timing on local heat fluxes, the ignition timing was varied around this MBT-timing. Again, heat flux measurements on methane combustion were performed at $\lambda=1$, those on hydrogen combustion at $\lambda=1.5$.

Figure 8 displays the effect of delaying or advancing the ignition timing with $12^{\circ} \mathrm{CA}$. The plot shows that increasing spark advance does not only advance the rising of the heat flux, but also generates higher peak heat fluxes for both fuels. This agrees with the measurements of Shudo et al. [20]. The higher heat fluxes are particularly caused by higher gas temperatures with increasing spark advance. IMEP varies a little bit around the maximum values for the MBT-timings, 7.5 bar for methane and $5.2 \mathrm{bar}$ for hydrogen. The maximum gas temperature for methane rises from 1770 to $2000{ }^{\circ} \mathrm{C}$, for hydrogen it increases from 1600 to $1680^{\circ} \mathrm{C}$. The higher peak in the heat flux trace causes an increase in the total cycle heat loss. The wall temperature rises from 160 to $195^{\circ} \mathrm{C}$ for methane and from 143 to $157^{\circ} \mathrm{C}$ for hydrogen.

\subsubsection{Air-to-fuel equivalence ratio}

Lean burn operation with methane is possible, but the slow initial phase of combustion at stoichiometric burning becomes even bigger at lean burn operation [27]. The range for $\lambda$, in which normal operation is possible, is narrower in comparison to hydrogen combustion. The maximal (theoretical) air-to-fuel equivalence ratio for methane combustion is about 2 and for hydrogen combustion this can go up to 10 [28]. As 
the flammability limits of methane are so small, measurements on methane were only conducted at $\lambda=1, \lambda=1.2$ and $\lambda=1$.4. Higher air-to-fuel equivalence ratios cause unacceptably high cyclic variations.

Figure 9 shows that a decrease in $\lambda$ (an increase in mixture richness) causes a higher peak and total cycle heat flux for methane and hydrogen. The heat flux also starts to rise earlier in the cycle because of a faster burn rate. The apparent rate of heat release is plotted as well to illustrate the change in combustion process with varying $\lambda$. The plot in Fig. 9(a) shows that the combustion of methane with $\lambda$ equal to 1.4 goes very slow. The ignition timing should be more advanced in order to optimize the engine operation. MBT-timings for all operation points will be used in future research. IMEP increases from 4.8 to 7.5 bar for the methane measurements and from 4.7 to 6.1 bar for the hydrogen ones. The wall temperatures increase as well, from 132 to $175^{\circ} \mathrm{C}$ for methane and from 133 to $184^{\circ} \mathrm{C}$ for hydrogen.

The total cycle heat loss divided by the released energy during combustion $\left(Q_{\text {fuel }}\right)$ is defined here as a cooling loss ratio $\phi_{h}$. Not only the amount of heat transfer increases with decreasing $\lambda$ but $\phi_{h}$ increases as well. For methane it increases from $14.7 \%$ to $20.4 \%$ for $\lambda$ varying from 1.4 to 1 . For hydrogen $\phi_{h}$ changes from $16.7 \%(\lambda=2)$ to $30.1 \%(\lambda=1)$. The heat transfer mainly increases because of a higher gas temperature. The maximum calculated gas temperature increases from 1200 to $1880^{\circ} \mathrm{C}$ for methane and from 1350 to $2030^{\circ} \mathrm{C}$ for hydrogen.

\section{A comparison between the methane and hydrogen heat fluxes}

It is clear that methane and hydrogen heat flux traces have completely different shapes. Due to the shorter burn duration, the width of the heat flux peak is much smaller for hydrogen combustion. This does not lead to lower total cycle heat losses however. In Fig. 10 the heat flux is compared between hydrogen and methane combustion with an equal indicated power output of about $375 \mathrm{~J}$. For methane the power output was lowered either by throttling the inlet flow or by running lean. The peak heat flux is clearly higher for hydrogen. Also the total heat loss of a cycle is higher for hydrogen as can be seen in Table 3. This agrees with results of other researchers given in the introduction. The wall temperature follows the same trend as the heat flux. The temperature varies from $147^{\circ} \mathrm{C}$ for the lean methane case to $184^{\circ} \mathrm{C}$ for hydrogen. The maximum gas temperature is higher for the measurement on hydrogen $\left(2030^{\circ} \mathrm{C}\right)$ than for the two measurements on methane $\left(1460^{\circ} \mathrm{C}\right.$ for the WOT measurement and $1880^{\circ} \mathrm{C}$ for the stoichiometric measurement) but it cannot be the only cause of the higher heat flux. The difference in maximum gas temperature between the two methane measurements is much higher compared to the difference between the stoichiometric measurement on methane and the one on hydrogen. The biggest difference in the heat flux occurs however between the last two measurements.

Although $\phi_{h}$ is almost twice as high for the measurement on hydrogen than for the WOT one on methane, the indicated thermal efficiency $\left(\eta_{i}\right)$ is only $3 \%$ smaller. This is because of the shorter burn duration for hydrogen. This trend was also visible in the measurements of Shudo et al. [20] as mentioned before. It was not the intention of this research to optimize the engine operation for maximum efficiency, but it is still interesting that the highest indicated thermal efficiency of all the test results was 
reached on hydrogen (30\% for the measurement with $\lambda=2$ displayed in Fig. 9(b)), although $\phi_{h}$ was always higher than for methane.

The throttled measurement on methane gives a higher peak and total cycle heat flux than the lean case, due to the higher mixture richness and an increased turbulence caused by throttling. This was the case for the motored measurements as well (see Fig. 4). It can also be deduced from $\phi_{h}$ which is higher for the throttled stoichiometric case displayed in Fig. 10 (24.1\%) than for the WOT stoichiometric measurement (20.4\%) plotted in Fig. 9(a).

Stoichiometric hydrogen combustion causes a heat flux peak of $3.3 \cdot 10^{6} \mathrm{~W} / \mathrm{m}^{2}$ which is two to three times the magnitude of the peak in the heat flux trace of stoichiometric methane combustion $\left(1.3 \cdot 10^{6} \mathrm{~W} / \mathrm{m}^{2}\right)$, see Fig. $9 . \phi_{h}$ is $31 \%$ for the stoichiometric hydrogen measurement and $20.4 \%$ for the one on methane. At $\lambda=1.5$ the peak heat flux on hydrogen is comparable to that of stoichiometric methane, but power output is only about $75 \%$ that of methane and $\phi_{h}$ is about $3 \%$ higher. The heat loss through the walls is considerably higher with hydrogen combustion, but it is nevertheless possible to reach higher indicated thermal efficiencies compared to methane.

\section{Conclusions}

In this work the use of a commercially available and calibrated thermopile sensor for heat flux measurements inside a combustion engine was demonstrated. Local instantaneous heat flux measurements were performed inside a spark-ignited CFR engine with a constant engine speed under motored and fired conditions. A comparison was made between operation on methane and hydrogen. The influence of throttle position, compression ratio, ignition timing and air-to-fuel equivalence ratio were examined.

- Turbulence caused by throttling increases the heat transfer at the end of the compression and the beginning of the expansion stroke.

- The peak of the heat flux increases and occurs earlier with increasing compression ratio. Total cycle heat losses can be smaller due to a lower heat flux at the end of the expansion stroke where the in-cylinder surface is larger.

- Advanced ignition timing causes an increase in the peak of the heat flux trace and therefore increases total cycle heat loss.

- Increasing $\lambda$ (decreasing mixture richness) gives lower heat fluxes. The moment where the heat flux starts to rise occurs later in the cycle because of a slower burn rate.

- Due to the unique combustion characteristics of hydrogen, less cyclic and spatial variations, higher peak and total cycle heat fluxes and a smaller lag between ignition and heat flux peak were observed compared to methane. It is however possible to reach higher indicated thermal efficiencies due to the shorter burn duration. 


\section{Acknowledgements}

The authors of this paper would like to acknowledge the suggestions and technical assistance of Rene Janssens, Koen Chielens and Patrick De Pue. The research is funded by a Ph.D. grant (SB-81139) of the Institute for the Promotion of Innovation through Science and Technology in Flanders (IWT-Vlaanderen).

\section{References}

[1] S. Verhelst, P. Maesschalck, N. Rombaut, R. Sierens, Increasing the power output of hydrogen internal combustion engines by means of supercharging and exhaust gas recirculation, International Journal of Hydrogen Energy 34 (10) (2009) 4406 -4412 .

[2] S. Verhelst, P. Maesschalck, N. Rombaut, R. Sierens, Efficiency comparison between hydrogen and gasoline, on a bi-fuel hydrogen/gasoline engine, International Journal of Hydrogen Energy 34 (5) (2009) 2504-2510.

[3] T. Wallner, H. Lohse-Busch, S. Gurski, M. Duoba, W. Thiel, D. Martin, T. Korn, Fuel economy and emissions evaluation of BMW Hydrogen 7 mono-fuel demonstration vehicles, International Journal of Hydrogen Energy 33 (24) (2008) 7607 -7618 .

[4] S. Verhelst, R. Sierens, A quasi-dimensional model for the power cycle of a hydrogen-fuelled ICE, International Journal of Hydrogen Energy 32 (15) (2007) $3545-3554$.

[5] S. Wei, A study on transient heat transfer coefficient of in-cylinder gas in the hydrogen fueled engine, in: Proceedings of the 6th Korea-Japan Joint Symposium on Hydrogen Energy, 2001.

[6] T. Shudo, H. Suzuki, Applicability of heat transfer equations to hydrogen combustion, Jsae Review 23 (3) (2002) 303-308.

[7] D. A. Bendersky, A special thermocouple for measuring transient temperatures, Mechanical Engineering 75 (1953) 117-121.

[8] W. J. D. Annand, Heat transfer in the cylinders of reciprocating internal combustion engines, Proc Instn Mech Engrs 177 (36) (1963) 973-996.

[9] D. R. Buttsworth, Transient response of an erodable heat flux gauge using finite element analysis, Proceedings of the Institution of Mechanical Engineers Part DJournal of Automobile Engineering 216 (D8) (2002) 701-706.

[10] G. Woschni, Determination of local heat transfer coefficients at the piston of a high speed diesel engine by evaluation of measured temperature distribution, SAE paper no. 790834 (1979). 
[11] B. Lawton, Effect of compression and expansion on instantaneous heat-transfer in reciprocating internal-combustion engines, Proceedings of the Institution of Mechanical Engineers Part a-Journal of Power and Energy 201 (3) (1987) 175186.

[12] D. J. O. Nijeweme, J. B. W. Kok, C. R. Stone, L. Wyszynski, Unsteady in-cylinder heat transfer in a spark ignition engine: experiments and modelling, Proceedings of the Institution of Mechanical Engineers Part D-Journal of Automobile Engineering 215 (D6) (2001) 747-760.

[13] M. L. G. Oldfield, Impulse response processing of transient heat transfer gauge signals, Journal of Turbomachinery-Transactions of the ASME 130 (021023) (2008) 1-9.

[14] X. Wang, P. Price, C. R. Stone, D. Richardson, Heat release and heat flux in a spray-guided direct-injection gasoline engine, Proceedings of the Institution of Mechanical Engineers Part D-Journal of Automobile Engineering 221 (D11) (2007) 1441-1452.

[15] J. Demuynck, S. Pauwels, S. Verhelst, M. De Paepe, R. Sierens, Experimental research on the heat transfer inside a hydrogen combustion engine: Evaluation and construction of measurement methods, in: Proceedings of the FISITA 2008 World Automotive Congress (paper no. F2008-SC-037), 2008.

[16] A. Wimmer, R. Pivec, T. Sams, Heat transfer to the combustion chamber and port walls of IC engines - measurement and prediction, SAE paper no. 2000-01-0568 (2000).

[17] A. Wimmer, T. Wallner, J. Ringler, F. Gerbig, H2-direct injection - a highly promising combustion concept, SAE paper no. 2005-01-0108 (2005).

[18] H. Eichlseder, G. Peter, G. Falk, H. Klaus, Advanced combustion concepts and development methods for hydrogen IC engines, in: Proceedings of the FISITA 2008 World Automotive Congress (paper no. F2008-06-103), 2008.

[19] J. Michl, M. Schenk, H. Rottengruber, W. Huhn, Thermal boundary conditions in a stoichiometric operating hydrogen engine, in: Proceedings of the FISITA 2008 World Automotive Congress (paper no. F2008-06-110), 2008.

[20] T. Shudo, Y. Nakajima, T. Futakuchi, Thermal efficiency analysis in a hydrogen premixed combustion engine, JSAE Review 21 (2) (2000) 177-182.

[21] T. Shudo, S. Nabetani, Analysis of degree of constant volume and cooling loss in a hydrogen fuelled SI engine, SAE paper no. 2001-01-3561 (2001).

[22] T. Shudo, Improving thermal efficiency by reducing cooling losses in hydrogen combustion engines, International Journal of Hydrogen Energy 32 (17) (2007) 4285-4293. 
[23] G. M. Wheeler, ASTM Manual for Rating Motor Fuels by Motor and Research Methods, American Society for Testing and Materials, Baltimore, 1964.

[24] J. R. Taylor, An Introduction to Error Analysis: The Study of Uncertainties in Physical Measurements, ISBN 0-935702-42-3, University Science Books, 1982.

[25] J. B. Heywood, Internal Combustion Engine Fundamentals, ISBN 0-07-028637X, McGraw-Hill, 1988.

[26] M. Namazian, S. Hansen, E. Lyford-Pike, J. Sanchez-Barsse, J. Heywood, J. Rife, Schlieren visualization of the flow and density fields in the cylinder of a sparkignition engine, SAE paper no. 800044 (1980).

[27] G. A. Karim, I. Wierzba, Y. Al-Alousi, Methane-hydrogen mixtures as fuels, International Journal of Hydrogen Energy 21 (7) (1996) 625-631.

[28] C. M. White, R. R. Steeper, A. Lutz, The hydrogen-fueled internal combustion engine: A technical review, International Journal of Hydrogen Energy 31 (10) (2006) 1292-1305. 
Table 1: Geometrical properties and valve timing of the CFR engine

\begin{tabular}{|c|c|}
\hline Bore & $82.55 \mathrm{~mm}$ \\
\hline Stroke & $114.2 \mathrm{~mm}$ \\
\hline Connecting rod length & $254 \mathrm{~mm}$ \\
\hline Swept volume & $611.7 \mathrm{~cm}^{3}$ \\
\hline IVO & $17^{\circ} \mathrm{CA} \mathrm{ATDC}$ \\
\hline IVC & $26^{\circ} \mathrm{CA} \mathrm{ABDC}$ \\
\hline EVO & $32^{\circ} \mathrm{CA} \mathrm{BBDC}$ \\
\hline EVC & $6^{\circ} \mathrm{CA}$ ATDC \\
\hline
\end{tabular}


Table 2: The accuracy of the measurement equipment

\begin{tabular}{l|l|l} 
Variable & Device & Accuracy \\
\hline Heat flux & HFM & $\pm 3 \%$ \\
Wall temperature & HFM & $\pm 5 \%$ \\
In-cylinder pressure & Kistler 701A & $\pm 0.5 \%$ \\
Intake manifold pressure & Kistler 4075A20 & $\pm 0.5 \%$ \\
Air flow rate & Bronkhorst F-106BZ & $\pm 1 \% F S$ \\
Hydrogen flow rate & Bronkhorst F-201AC & $\pm 1 \% F S$
\end{tabular}


Table 3: Comparison between heat losses from hydrogen and methane combustion

\begin{tabular}{c|c|c|c|c|c|c|c} 
fuel & $\lambda$ & throttle & $Q_{\text {fuel }}(\mathrm{J})$ & $W_{i}(\mathrm{~J})$ & $\eta_{i}(\%)$ & $Q_{h}(\mathrm{~J})$ & $\phi_{h}(\%)$ \\
\hline methane & 1.25 & WOT & 1345 & 377 & 28.0 & 235 & 17.5 \\
methane & 1 & pos 73 & 1407 & 373 & 26.5 & 339 & 24.1 \\
hydrogen & 1 & WOT & 1535 & 375 & 24.4 & 475 & 31.0
\end{tabular}



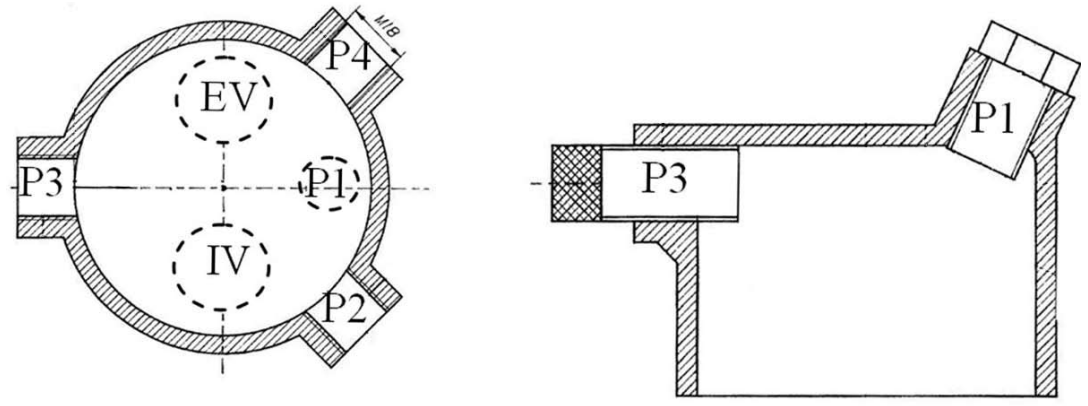

Figure 1: Cross section of the CFR engine, P1: spark plug, P2-P4: sensor positions, IV: intake valve, EV: exhaust valve

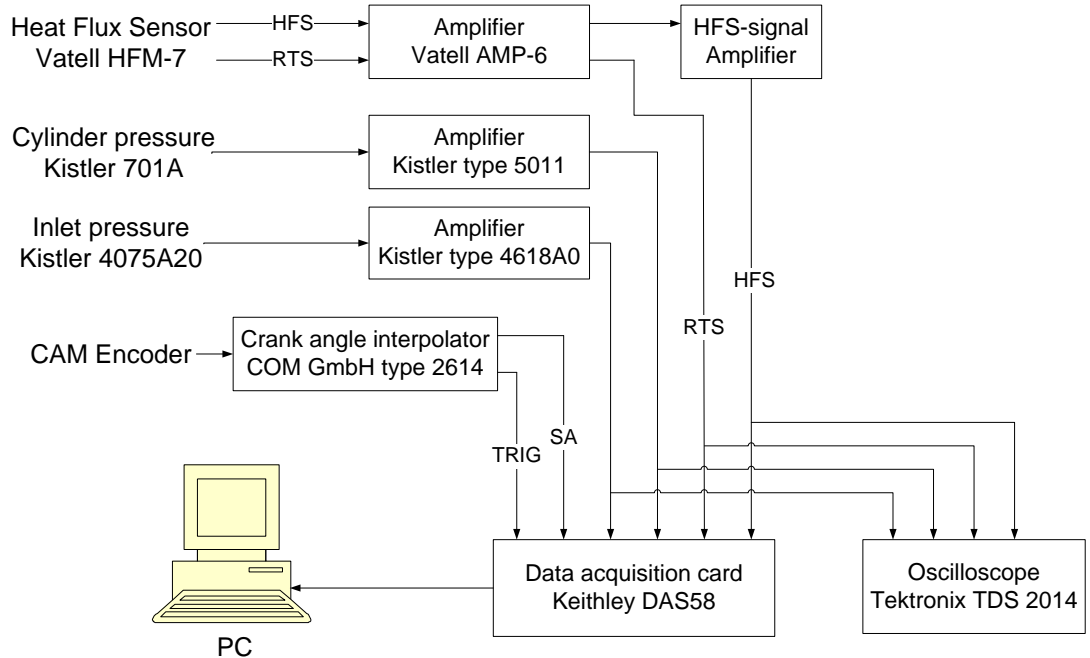

Figure 2: Measuring equipment, HFS: heat flux signal, RTS: substrate temperature signal, TRIG: trigger signal every two cycles, SA: sample signal every $0.1^{\circ} \mathrm{CA}$ 


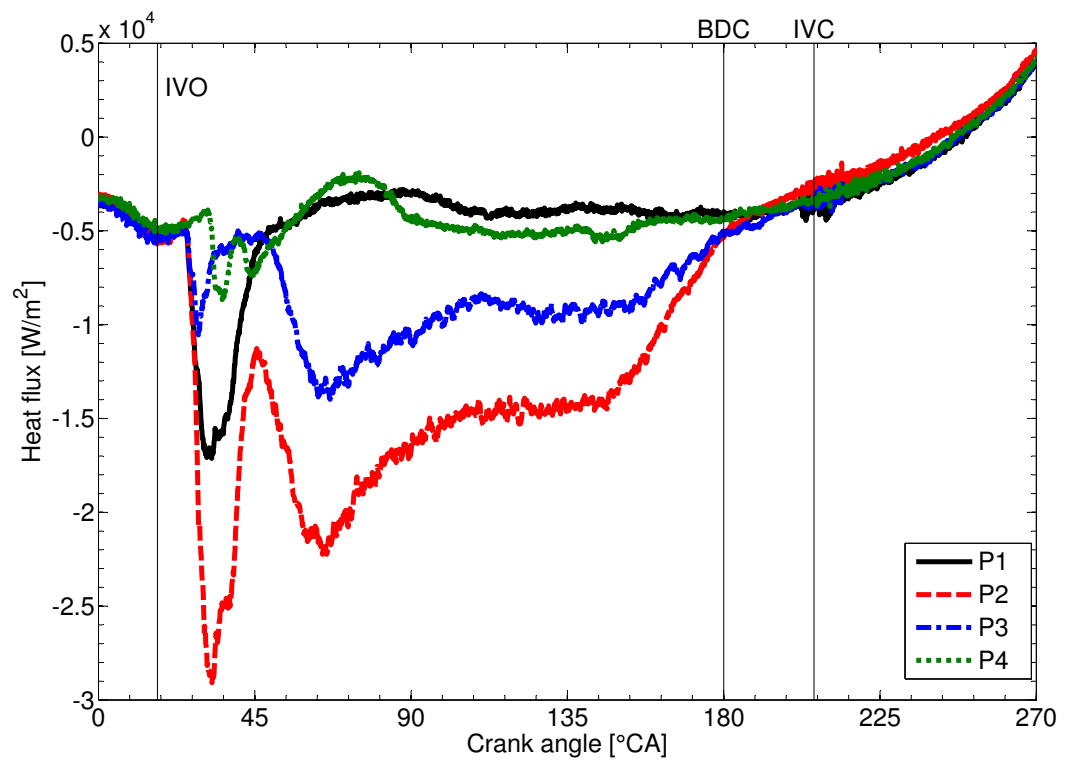

(a) intake stroke

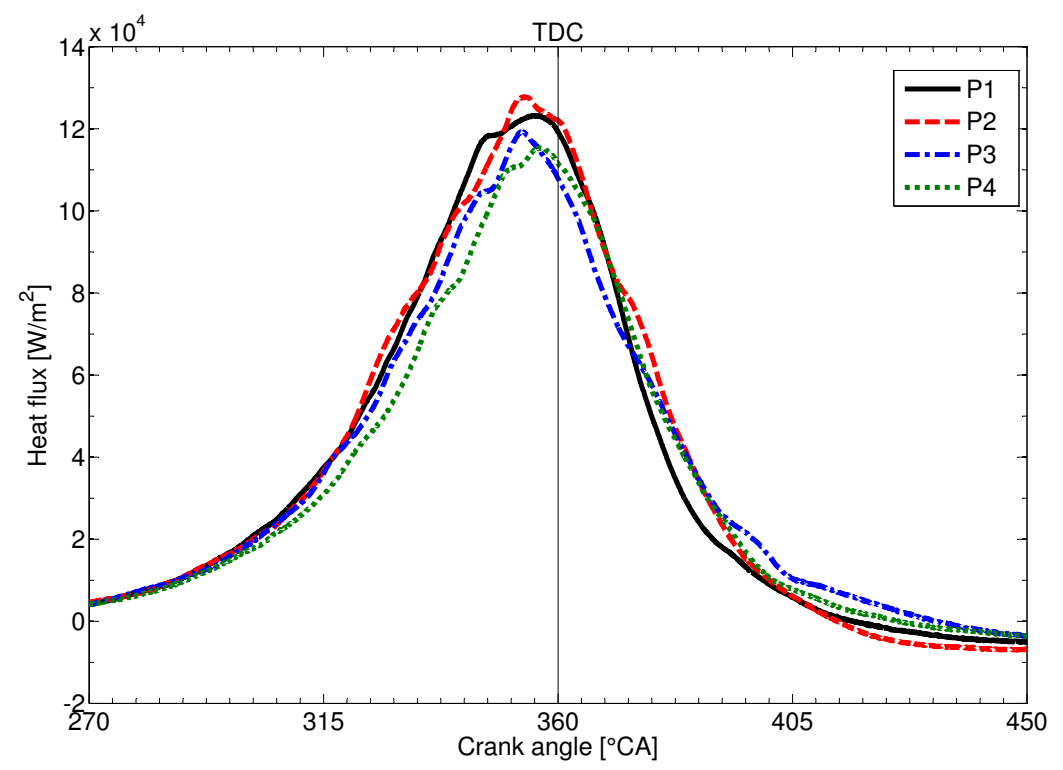

(b) compression and expansion stroke

Figure 3: Influence of measuring position on local heat flux under motored conditions $(\epsilon=10)$ 


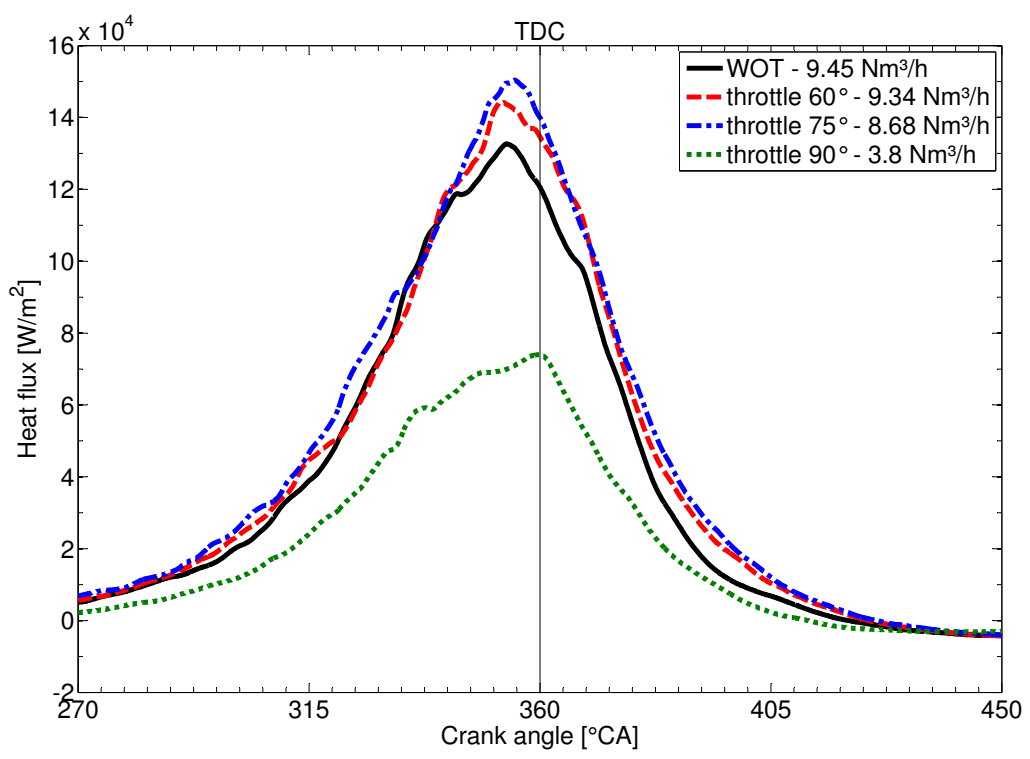

Figure 4: Influence of throttling on local heat flux under motored conditions $(\epsilon=10, \mathrm{P} 1)$ 


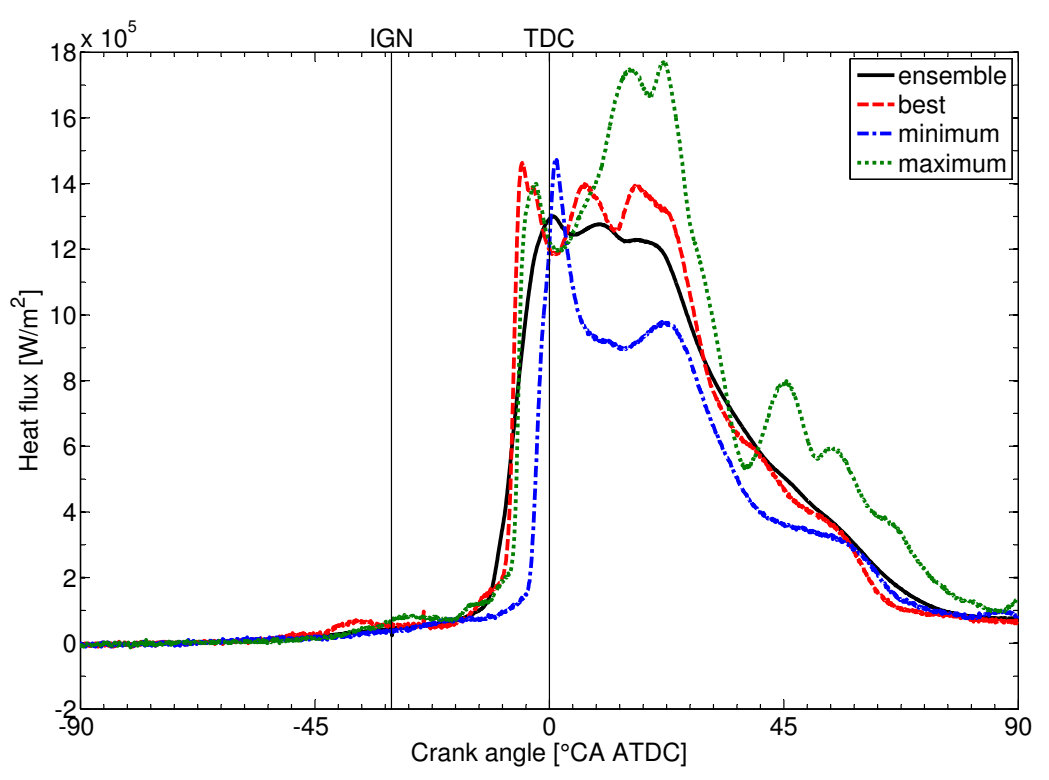

(a) Methane (IMEP=7.9 bar)

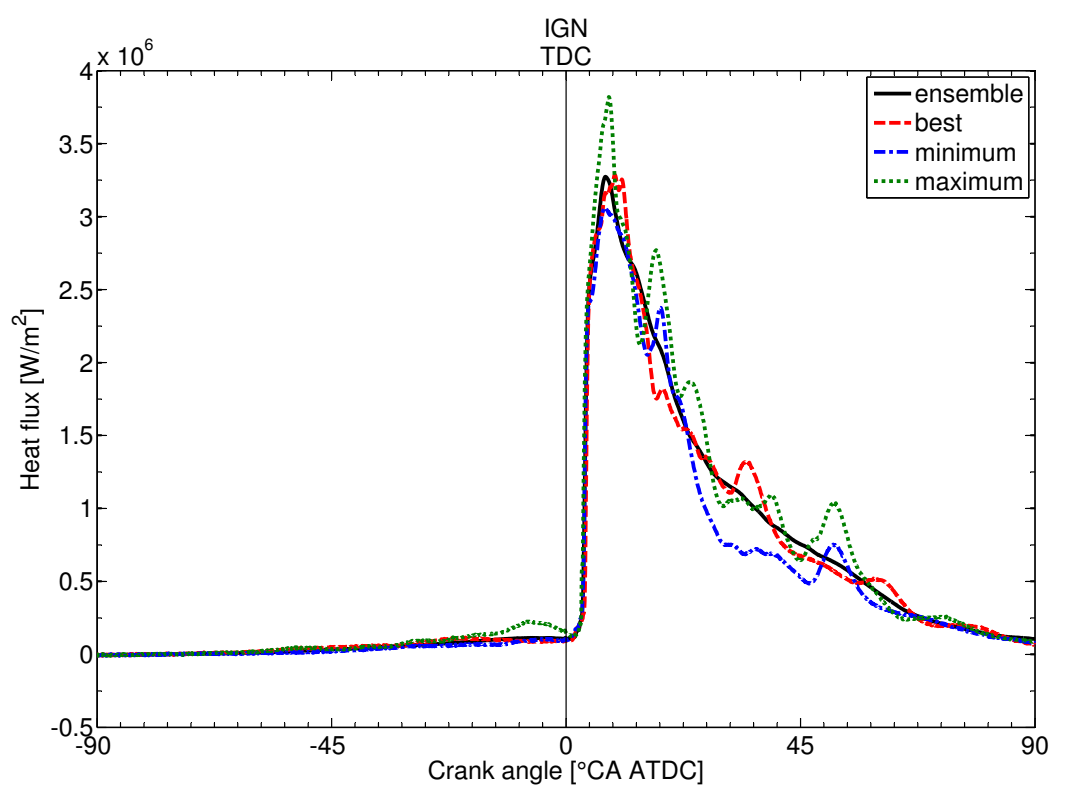

(b) Hydrogen (IMEP=5.9 bar)

Figure 5: Cyclic variation of local heat flux $(\epsilon=8, \lambda=1, \mathrm{P} 2)$ 


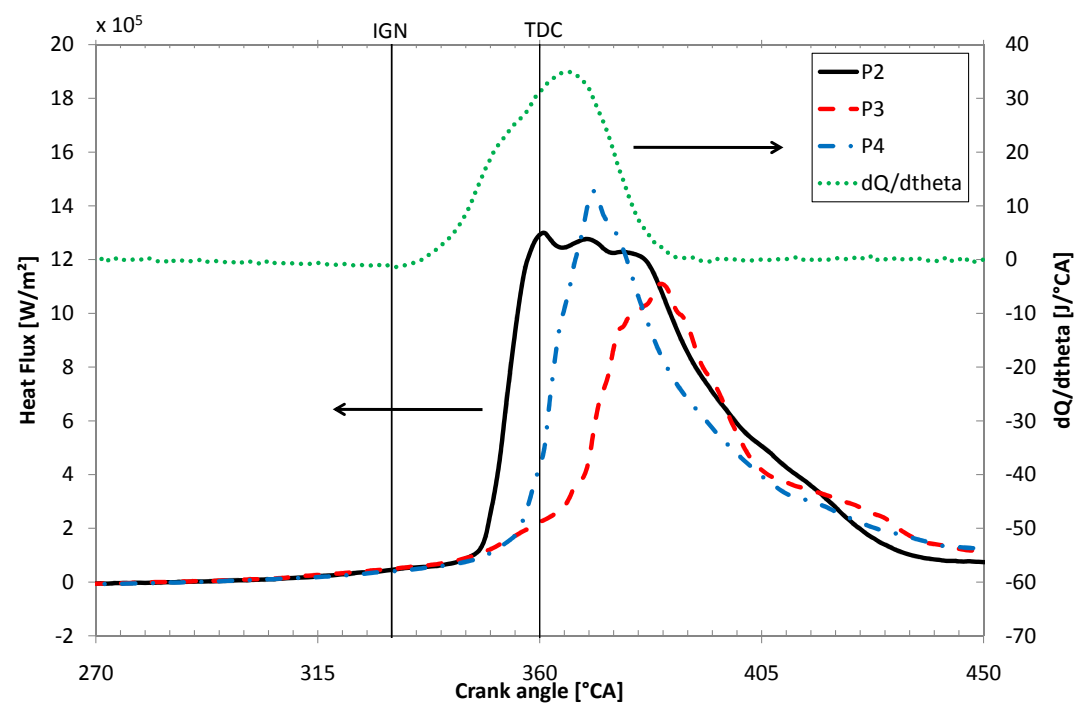

(a) Methane (IMEP=7.9 bar)

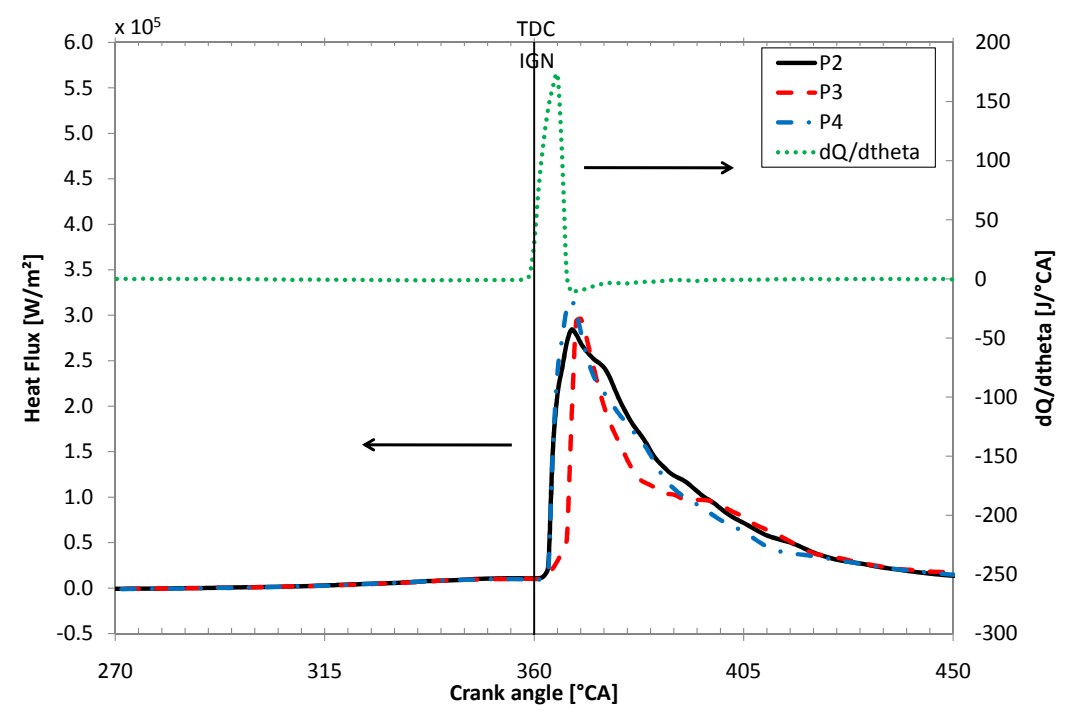

(b) Hydrogen (IMEP=5.9 bar)

Figure 6: Influence of measuring position on local heat flux $(\epsilon=8, \lambda=1)$ 


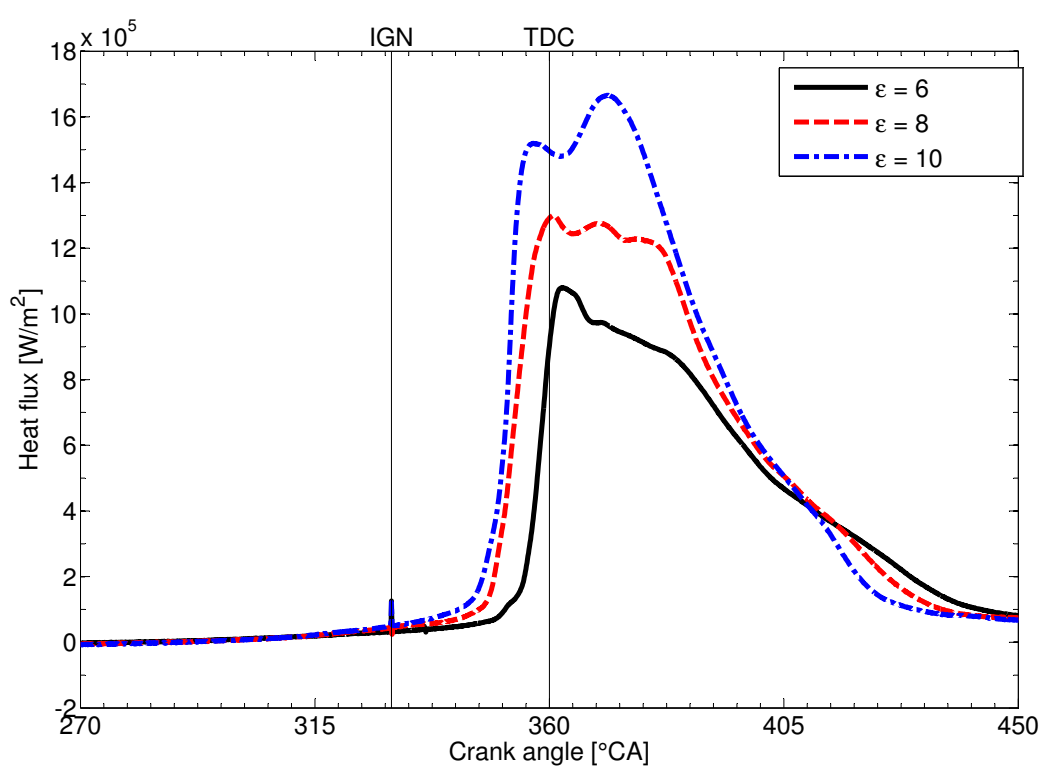

(a) Methane $(\lambda=1)$

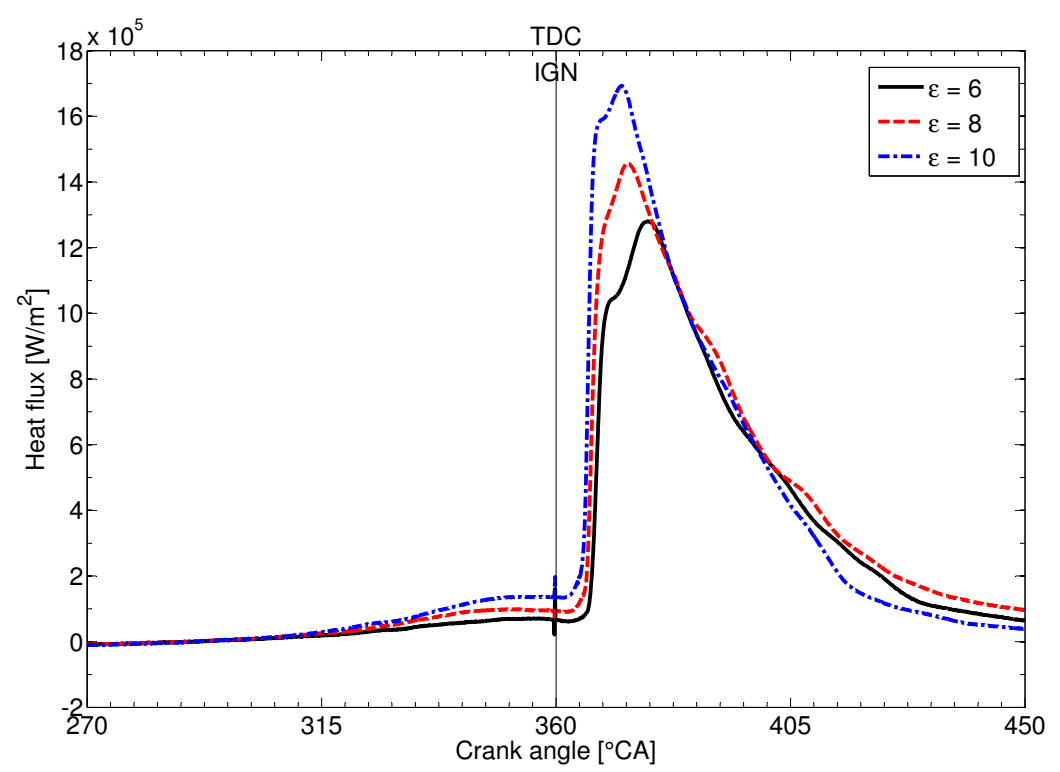

(b) Hydrogen $(\lambda=1.5)$

Figure 7: Influence of compression ratio on local heat flux (P2) 


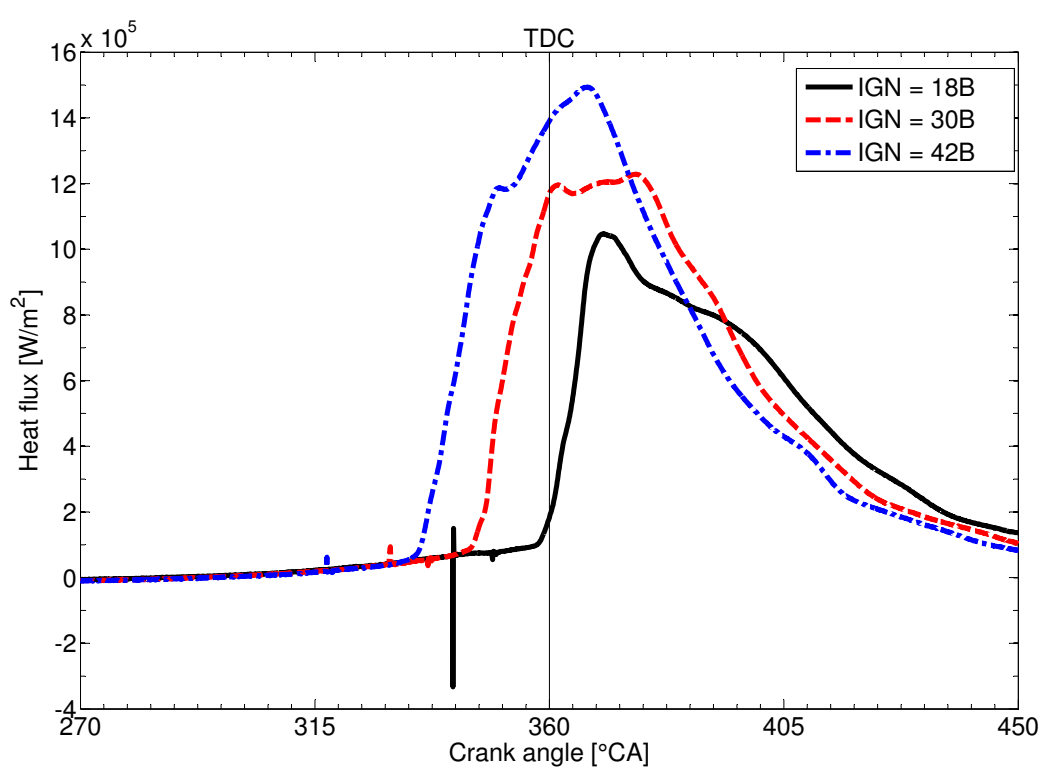

(a) Methane $(\lambda=1)$

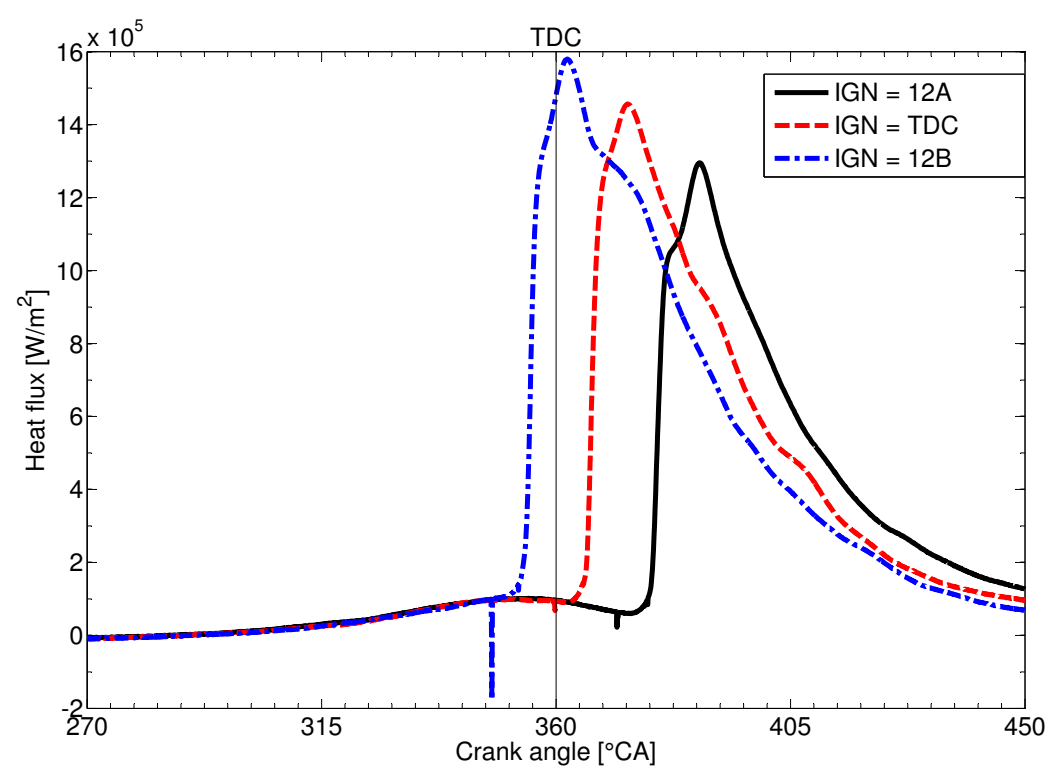

(b) Hydrogen $(\lambda=1.5)$

Figure 8: Influence of ignition timing on local heat flux $(\epsilon=8, \mathrm{P} 2)$ 


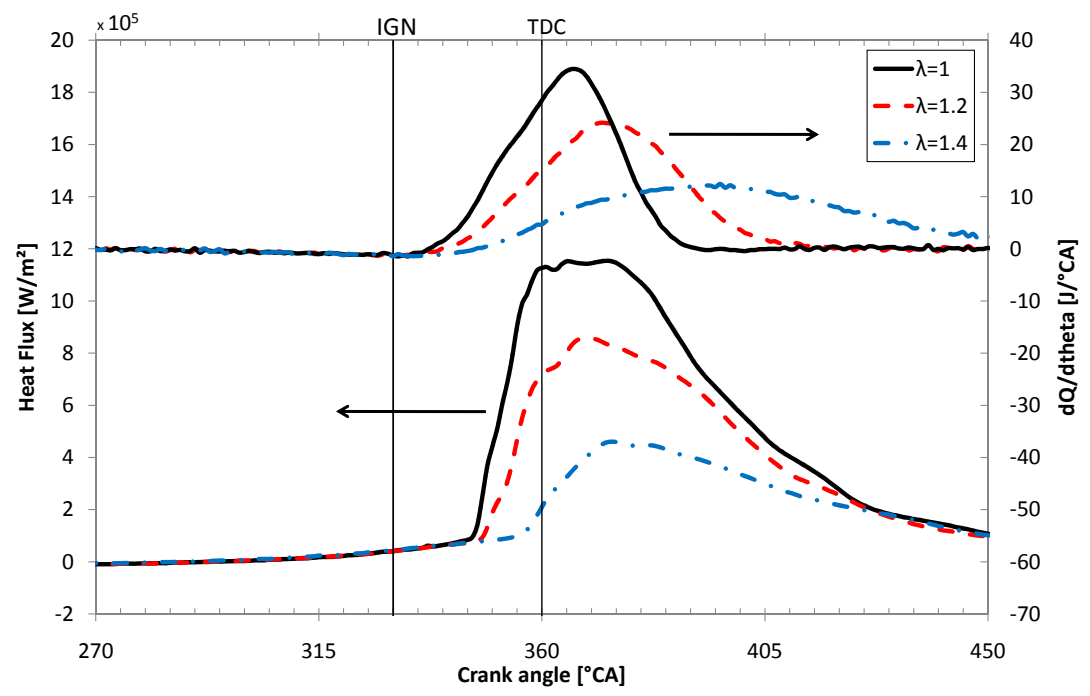

(a) Methane

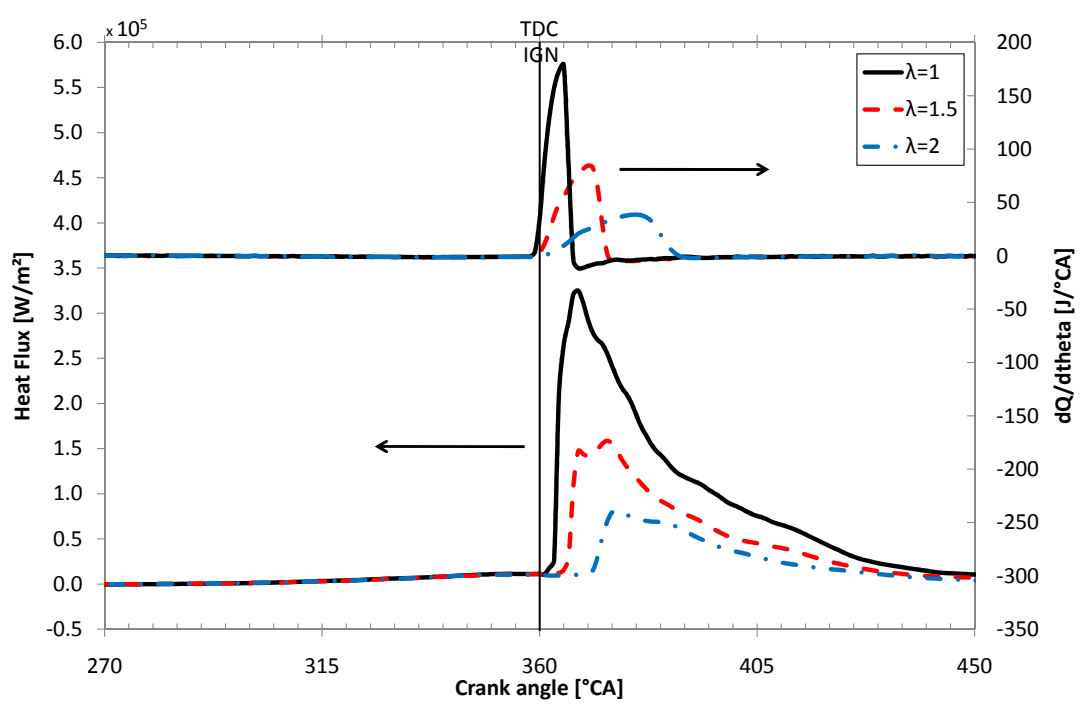

(b) Hydrogen

Figure 9: Influence of $\lambda$ on local heat flux $(\epsilon=8, \mathrm{P} 2)$ 


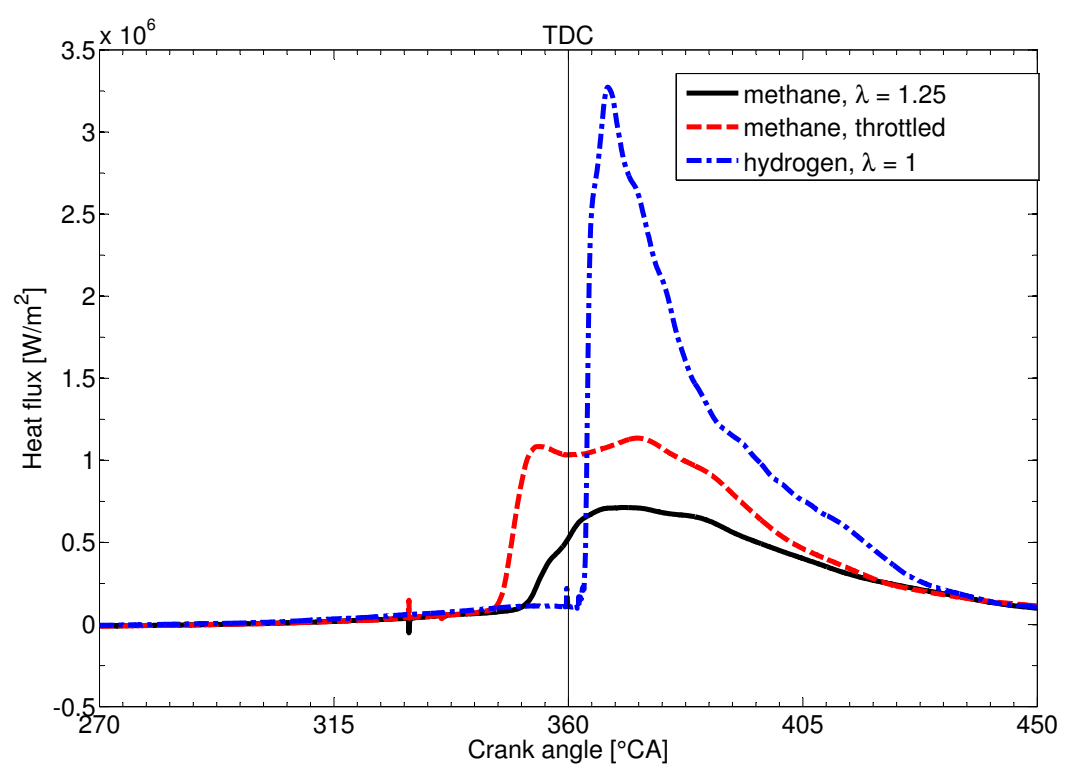

Figure 10: Influence of fuel on local heat flux with equal power output $(\epsilon=8, \mathrm{P} 2)$ 